\title{
Multi-stage forging on torx-pin screw with high torque
}

\author{
Gow-Yi Tzou', Dyi-Cheng Chen ${ }^{2}$ and Shih-Hsien Lin ${ }^{2, a}$ \\ ${ }^{1}$ Department of Mechanical and Automation Engineering, Chung-Chou University of Science and Technology, \\ Chang-hua County 510, Taiwan \\ ${ }^{2}$ Department of Industrial Education and Technology, National Chang-Hua University of Education, Chang-hua \\ County 500, Taiwan
}

\begin{abstract}
The study assumes constant shear friction to simulate multi-stage forging on torx-pin screw with high torque using FEM commercial software. Because the screw head has a plum needle shape with the effect of high torque, the 3D simulation model is used to explore the effective stress, the effective strain, the velocity field, and the forging force in each stage. The forming pass schedule considers three stages to obtain the product, and uses the Deform-3D software to explore the feasibility of forming pass schedule. Finally, the realistic manufacturing of torx-pin screw can be carried out to compare with the simulation results to verify the acceptance of FEM simulation. The maximum dimension error between simulation and experiment is around $2.45 \%$, thus the feasibility of FEM simulation to die design for manufacturing the torx-pin screw can be verified.
\end{abstract}

\section{Introduction}

Screw \& nut products are categorized into the fastener. Screw \& nut can be divided into two main types. One is the threaded fastener, including screw, bolt, stud and nut; and the other is the nonthreaded fastener, including rivet, washer and hook. In general, screws are indicated the threaded products with smaller diameters, such as hex bolt, square-head bolt, foundation bolt, T-shape bolt, etc. How to manufacture the fasteners with low cost is still very important. Generally speaking, when selecting appropriate tool designs to manufacture the fasteners, it needs to consider whether these methods satisfies the production conditions, such as the number of stages, the forging force for the individual stage and whole forging process, the diameter of wires, the dies and the length of front/rear punch. Additionally, the simulation of tool design needs to know distribution of effective strain and stress for final products, and the forging force for each stage also needs to be controlled within a proper range. $\mathrm{Li}$ and $\mathrm{Oh}$ el al.[1-2] think that the design ways of multi-stage tool design are generally depended on subjective working experience and technologies of designers, but there still have insufficient experiences or undistributed considerations. For the manufacture of product, the most important issue is that how to use the lowest costs including money and time to produce the best products. Therefore, in order to shorten the lead time of the tool designs, reducing the cost of dies and using proper tool designs for machines are needed. Of course it is necessary to look for effective methods. In recent years, due to accelerating computation and lowering cost of computers, it makes a significant advancement of design and development in metal forming using Finite Element Method

\footnotetext{
${ }^{a}$ Corresponding author : fitrc@yahoo.com.tw
} 
(FEM), especially when it produces a more precise, rapid and stable simulation tool. Oh et al. [2] use the FEM DEFORM software to discover the damage causes of die and the die elastic deformation phenomenon during the cold forging.

Shih et al. [3] and Hsia [4] use the simulation analysis software, except for greatly increasing the efficiency of making dies, shortening the production cycle of new products and increasing the lifespan of dies, it also can provide new-coming designers with the prompt understanding of tool design, the analysis of defect and the improvement of simulation. Therefore, it can save massive time in preprocess schedule to further upgrade the design level of dies. Lange et al. [5] applies various computeraid simulation analyses (NASTRAN, ANSYS, DEFORM, ABAQUS, I-DEAS) to analyze the stress distribution on cold-forging die to predict the damage positions of the die, as well as conducted experiments to investigate the impact of the die curve fillet dimension and incline angle, surface treatment used and the hardness of various materials and thermal treatment on the service life of die. Nagao et al. [6] use the finite element software DEFORM to analyze the car forging parts and compare the optimal designed stress ring of die, to understand the pressure phenomenon forced on die, in order to increase the service life of die. Knoerr et al. [7] use the integrated computer-aid simulation analysis system to calculate the force for the cold forging die, in order to investigate the problem points of over-force damage or fatigue damage. Wang et al. [8] make improvements in the defective phenomenon, such as folding that caused by the flowing of blank. They adopt the feature-based method with focusing on the location and timing of occurring defects to complete these feature requirements for these problems in early stages before redesigning the tool designs, also fix these features to avoid occurring the defective phenomenon with initiating feature requirements that caused by the material flowing in follow-up forming stages again. Shih et al. [9] and Sun et al. [10] explore that when the bolt is forging and forming, its tensile strength would be influenced by the crack of forging stream line. Therefore, the simulation Simufact software is used to know the cause of cracking the forging stream line, changing tool designs to reduce the number of cracked forging stream lines, and then improving bolt finished products' tensile strength. Chang et al. [11] aims at analyzing the influence of the maximum principal stress on Tungsten Carbide Steel die core in an extrusion die which caused the crack of die core, and then adjusts the dies assembly method in order to improve the service life of die.

This study mainly investigates that how to plan the forming pass schedule how many stages can be used to obtain the product, and uses the Deform-3D software to explore the feasibility of forming pass schedule. Finally, the realistic manufacturing of plum needle screw can be carried out to compare with the simulation results to verify the acceptance of FEM simulation.

\section{Finite element method}

Finite Element Method (FEM) is a numerical method to analyze product parts or assembly systems, in order to make sure of the entire product development cycle and function's consistency, its main spirit is still focusing on changing the questions with limitless freedom to be finite freedom, and then sort out the required approximation with using the numerical method. FEM function is to design the geometric model, after carrying out the finite element analysis to understand the structural response (deformation, stress, temperature, etc.), and the calculated results can be showed in graphs and diagrams. If in the design compared the calculated stress value and tolerance or maximum value, when it failed the design requirement, then the structure needs to re-design and re-analyze until reaching the acceptable design values.

FEM's applications of the plastic forming can be divided into the elastic FEM and rigid-plastic FEM, and FEM is the most common method to analyze the plastic deformation for materials. According to the work patterns and geometric shape of objects, tools and materials are segmented into several elements (triangle, tetragon, tetrahedron or hexahedron), so as to solve the stiffness matrix for individual element, then reconsider the material stress and strain model to get the structural equations, and cooperate with the stress and strain relations and boundary condition to compute the force, deformation, stress and strain distribution by computers. 
(1) Elastic-plastic Model

For the elastic-plastic model, assuming the deformation of materials including the recoverable and unrecoverable plastic deformation, which can provide the material flow information, including stress distribution, forming force, residual stress and strain distribution; therefore, its applicable range is comprehensive; however, in terms of the numeric computation, since varied material flow types between elastic and plastic deformation, it needs to inspect whether the deformation of every element is in the elastic or plastic range or not, thus the increment of deformation time should be very small, which is the economic defect for this computing method.

(2) Rigid-plastic Model

For the rigid-plastic materials, assuming it is an ideal material ignoring its elastic properties, thus certainly simplify the solving process when carrying out the analysis, thus the material stress distribution is mainly dependent on the strain when deforming. Even the rigid-plastic mode analysis couldn't obtain the distribution of residual stress, but it could be applied to the metal forming analysis, which could allow bigger increment for the deformation time; as a result, its computation is better.

\subsection{DEFORM-2D (3D) software}

It is mainly in an integrated environment to integrate with the modeling, forming, heat conducting and property of forming equipment to carry out the simulation analysis. In addition, it is applied for the cold, hot and warm forming with providing valuable engineering analytical data, such as material flow, die filling, forming force, die stress, grain flow, metal microstructure and defect yielding status, etc. These complicated 3D parts and die are the target to be treated. Also, it obtains the effective stress, effective strain, velocity field and forming force of every stage for the forging part, and greatly increases the service life of die. The simulation of the forging part is almost as same as the actual product. Among many finite element simulation analysis software, DEFORM-2D (3D) is the most optimal one of carrying out the simulation of fastener forging, thus this study is applied DEFORM-3D to conduct the die design and improvement of the high-torque torx-pin screw.

\subsection{Simulations of torx-pin screw}

Because the torx-pin head is not axial symmetrical, Deform-2D is unable to simulate it. It has to use the DEFORM-3D to implement an advanced and precise simulation, and the stages of its forming schedule are shown in Fig. 1, and wire $\operatorname{rod}(\phi 7.75$ X $22.30 \mathrm{~mm}$, the material is AISI4140) is needed 3 stages to conduct the product, where the part of torx-pin head at the 3rd stage has the most difficulty to compete, as shown in Fig. 2. At the $1^{\text {st }}$ stage, a forward extrusion method will be used to reduce the outer diameter of material from $\phi 7.75 \mathrm{~mm}$ to $\phi 5.20 \mathrm{~mm}$, at the $2^{\text {nd }}$ stage it is pre-forming the round head, and at the $3^{\text {rd }}$ stage the workpiece at the $2^{\text {nd }}$ stage can be formed to the required dimension, as well as the torx-pin head can be formed at the 3rd stage.
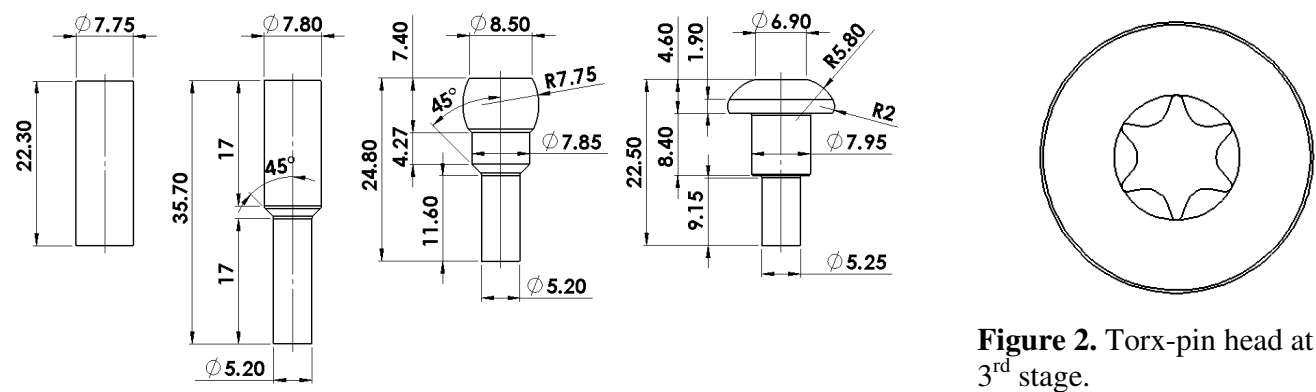

Figure 2. Torx-pin head at the $3^{\text {rd }}$ stage.

Figure 1. Forming schedule for each stage. 


\subsubsection{Mesh convergence analysis}

The main function of the mesh convergence analysis is to find the optimal mesh numbers to obtain more precise analytic results with using the $1^{\text {st }}$ stage as the analytic subject. As shown in Fig. 3 and Table 1, the analysis mesh numbers are between 50000 to 130000 , and according to the forging force to observe the force change in every increase of 10,000 mesh and capture the most stable value of force, its error should be controlled within $\pm 1 \%$. These results also can be showed by the convergence error, and the least error would be used to conduct the analysis for each stage. The least error obtained from the mesh convergence analysis that is $0.979 \%$, thus Model 8 should be adopted, and the mesh numbers used in this $3 \mathrm{D}$ research would be 120,000 .

Convergence Conditions can be wrote as:

$$
\text { Convergence error }(\%)=\frac{\text { Resul }_{\mathrm{N}}-\text { Result }_{\mathrm{N}-1}}{\text { Result }_{\mathrm{N}}} * 100 \%
$$

where

Result $_{\mathrm{N}}$ : current process; Result ${ }_{\mathrm{N}-1}$ : previous process

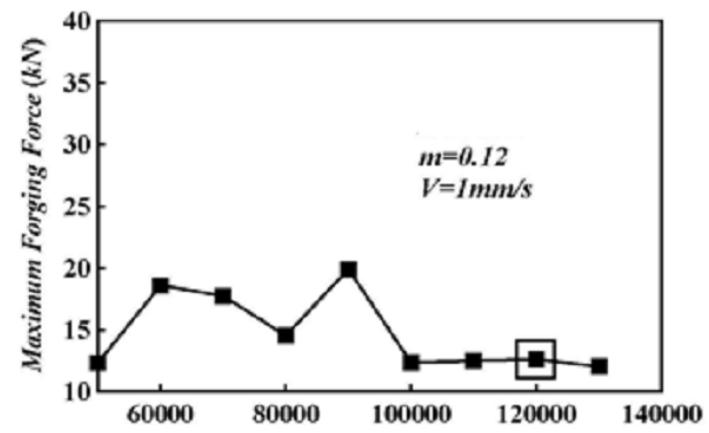

Figure 3. Mesh convergence analysis diagram for forging force.

Table 1. Mesh convergence analysis.

\begin{tabular}{|llllllllll|}
\hline Model & 1 & 2 & 3 & 4 & 5 & 6 & 7 & 8 & 9 \\
Mesh & 50000 & 60000 & 70000 & 80000 & 90000 & 100000 & 110000 & 120000 & 130000 \\
Force $(\mathrm{kN})$ & 12.338 & 18.589 & 17.739 & 14.535 & 19.918 & 12.353 & 12.488 & 12.611 & 12.027 \\
Error $(\%)$ & & 33.625 & -4.792 & -22.045 & 27.026 & -61.24 & 1.078 & 0.979 & -4.853 \\
\hline
\end{tabular}

\subsubsection{Pre-process setting}

The actual material of the torx-pin screw is AISI4140 with higher hardness; the flow stress is used from the data base in the software. With a view to understanding the convergent effect of mesh numbers, the mesh convergence analysis is considered the mesh number from 50,000 to 130,000; the optimal mesh number is discovered to be 120,000 meshes. The simulation conditions in this study is shown in Table 2; the frictional factor sets at $\mathrm{m}=0.12$ according to the defaulted cold forming in Deform software, and the punch velocity is assumed to be $1 \mathrm{~mm} / \mathrm{s}$ due to the cold forming process, as well as after using SolidWorks to make drawing, then imports the geometry of $3 \mathrm{D}$ drawing into the DEFORM-3D to conduct the analytic research.

Table 2. Analytic parameters for 3D simulation.

\begin{tabular}{||l||c||}
\hline Workpiece & AISI4140 \\
\hline \hline Young's Modulus $(E)$ & $206.754 \mathrm{GPa}$ \\
\hline \hline Poisson's Ratio $(v)$ & 0.3 \\
\hline \hline Flow stress & Defaulted \\
\hline \hline
\end{tabular}




\begin{tabular}{||l||c|}
\hline \hline Object type & Plastic \\
\hline \hline Number of Elements & 120,000 \\
\hline \hline Front die & WC \\
\hline Velocity $\left(V_{\mathrm{o}}\right)$ & $1 \mathrm{~mm} / \mathrm{s}$ \\
\hline Frictional factor $(m)$ & 0.12 \\
\hline Rear die & $\mathrm{WC}$ \\
\hline \hline Velocity $\left(V_{\mathrm{o}}\right)$ & $0 \mathrm{~mm} / \mathrm{s}$ \\
\hline Frictional factor $(m)$ & 0.12 \\
\hline
\end{tabular}

\subsection{Die design}

This study uses SolidWorks to design individual stage die, as shown in Fig. 4, after drawing the files would be saved as the STL format, which would conveniently read in the DREFORM software. In this study, designing the 3D upper die torx-pin punch, the rear punch also added to make the workpiece to be easily kicked out from the die. Moreover all dies are made of Tungsten Carbide.

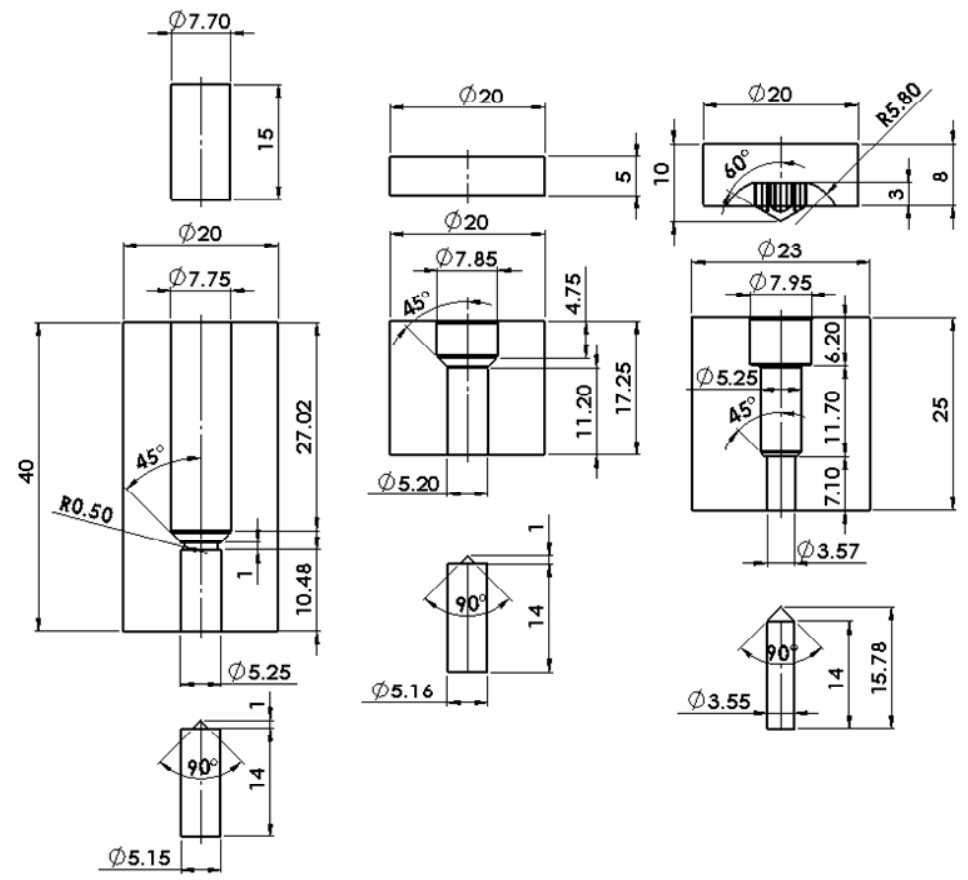

Figure 4. Die design diagram for each stage.

\section{Results and discussions}

\subsection{Forming simulation analysis at the $1^{\text {st }}$ stage}

After completely designing the die, input it into DEFORM-3D to conduct the analysis simulation, and complete the positioning process of the die and workpiece during pre-process. In Fig. 5, it shows the $1^{\text {st }}$ stage die forging, and Table 1 is used as the setting reference for each parameter. After undergoing the mesh convergence analysis, the obtained mesh numbers is 120,000 , the friction factors for the upper and bottom dies is 0.12 , the cold forging analysis is adopted, thus disregards the heat conducting, the front punch velocity is $1 \mathrm{~mm} / \mathrm{s}$, and the die is made of Tungsten Carbide. 


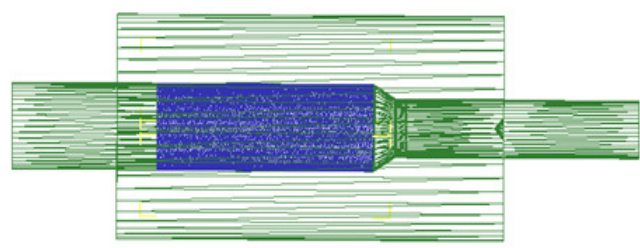

(a) Before forming

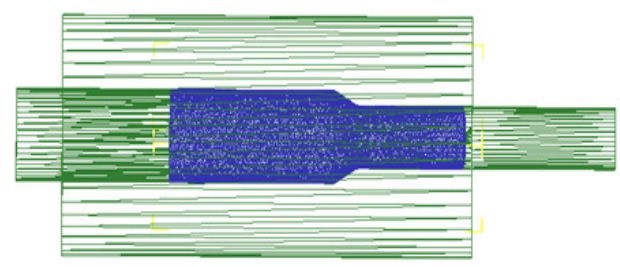

(b) After forming

Figure 5. Die assembly diagram of the $1^{\text {st }}$ stage before and after forging.

After completing the pre-process setting, it starts to conduct the simulation analysis. After finishing the analysis, with post-treatment, it can be known about the effective stress, strain, velocity field, and forging force. Fig. 6(a) is the effective stress diagram, and from this diagram, it is noted that the stress is mainly centralized on the connecting position of the shrinking outer diameter, which is similar to the extrusion forging, thus the maximum effective stress could be reached to $1590 \mathrm{MPa}$. Fig. 6(b) is the effective strain diagram, the strain is occurred on the small diameter, and the maximum effctive strain is $4.97 \mathrm{~mm} / \mathrm{mm}$. Fig. 6(c) is the velocity field distribution diagram, all materials would be flew downwardly, which the flow rate is rapid on the small diameter, and the highest flow rate is $2.99 \mathrm{~mm} / \mathrm{sec}$. The maximum forging force could be reached to $97.03 \mathrm{kN}$, as showen in Fig. 7 .

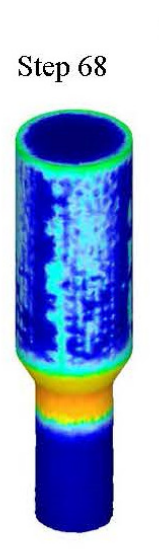

(a) Effective stress

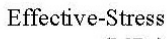

(MPa)

1590

1060

532

1.63

$1.63 \mathrm{Min}$

$1590 \mathrm{Max}$

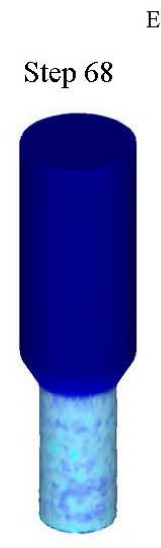

(b) Effective strain
Effective-Strain

$(\mathrm{mm} / \mathrm{mm})$

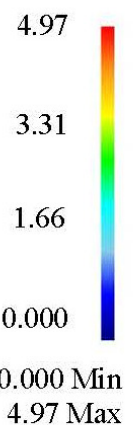

$4.97 \mathrm{Max}$
Velocity

$(\mathrm{mm} / \mathrm{sec})$

Step 68

2.99

2.28

1.58

0.881

0.881 Min

$2.99 \mathrm{Max}$

Figure 6. Effective stress, effective strain, and velocity field at the $1^{\text {st }}$ stage.

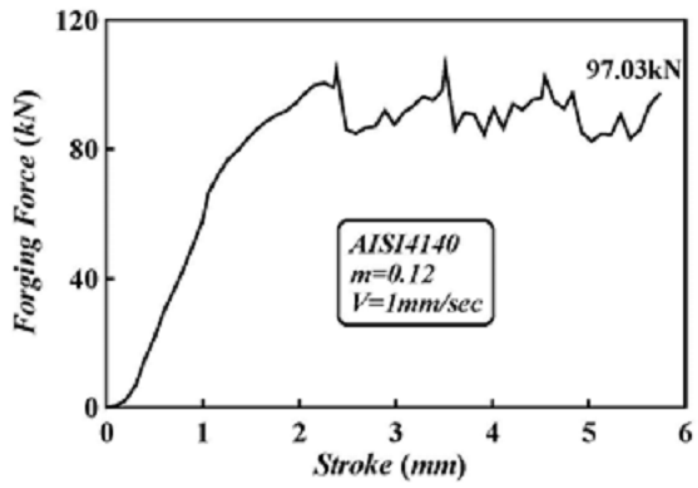

Figure 7. Forging force at the $1^{\text {st }}$ stage. 


\subsection{Forming simulation analysis at the $2^{\text {nd }}$ stage}

Using the workpiece completed at the 1 st stage forging to conduct the $2^{\text {nd }}$ stage forging, replacing the die with the design die at the $2^{\text {nd }}$ stage, after positioning the workpiece and die, setting parameters, as shown in the Fig. 8, which is the die assembly diagram of the $2^{\text {nd }}$ stage before and after forging formation.

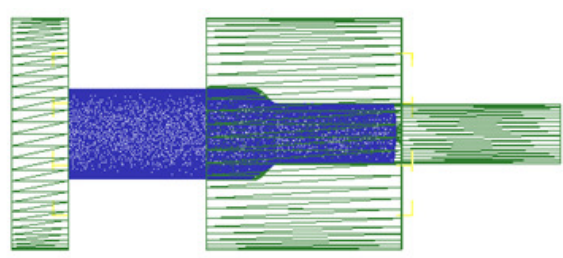

(a) Before forming

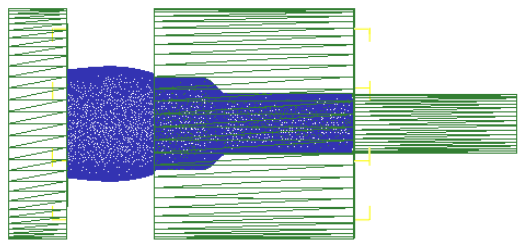

(b) After forming

Figure 8. Die assembly diagram of the $2^{\text {nd }}$ stage before and after forging.

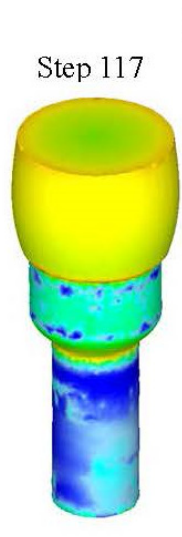

(a) Effective stress
Effective-Stress

(MPa)

1580

1060

537

14.7

14.7 Min $1580 \mathrm{Max}$
Effective-Strain

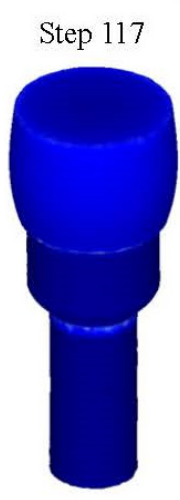

(b) Effective strain

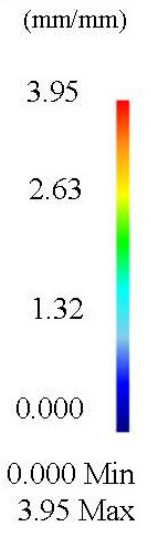

$0.000 \mathrm{Min}$
3.95 Max

(c) Velocity field
Velocity $(\mathrm{mm} / \mathrm{sec})$

1.04

0.696

0.348

0.000418

0.000418

Min

$1.04 \mathrm{Max}$

Figure 9. Effective stress, effective strain, and velocity field at the $2^{\text {nd }}$ stage.

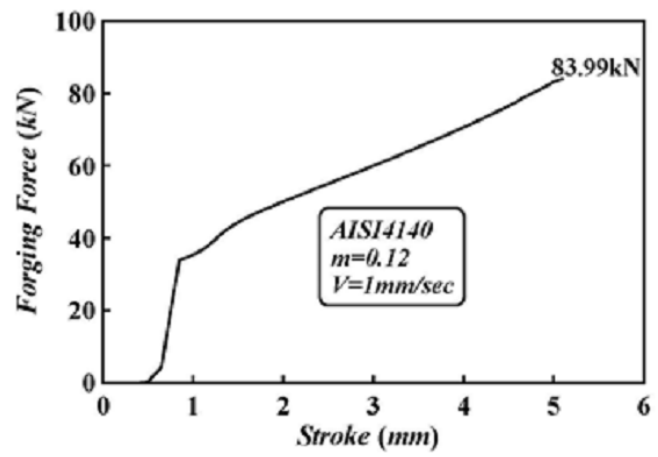

Figure 10. Forging force at the 2nd stage.

The $2^{\text {nd }}$ stage is mainly used to make the pre-form process for the top at the 3rd stage, after completing the simulation analysis at the $2^{\text {nd }}$ stage, it would obtain the effective stress, effective strain, 
velocity field, and forging force. Fig. 9(a) is the effective stress diagram, and from this diagram it is noted the stress is mainly centralized on the top round head, the maximum effective stress could be reached to $1580 \mathrm{MPa}$, the effective strain diagram is shown in Fig. 9(b), the maximum sffective strain is occurred on the top round head, and its maximum strain is $3.95 \mathrm{~mm} / \mathrm{mm}$. The velocity field distribution diagram is shown in Fig. 9(c), the materials are flew downward, and flew outward on the round head part, and the material flow status is very even. As shown in Fig. 10, the maximum forging force could be reached to $83.99 \mathrm{kN}$.

\subsection{Forming simulation analysis at the $3^{\text {rd }}$ stage}

Using the workpiece completed at the $2^{\text {nd }}$ stage to conduct the $3^{\text {rd }}$ stage forging, replacing the die with the design die at the $3^{\text {rd }}$ stage, after positioning the forging piece and die, setting parameters, as shown in the Fig. 11, which is the die assembly diagram at the $3^{\text {rd }}$ stage before and after forging.

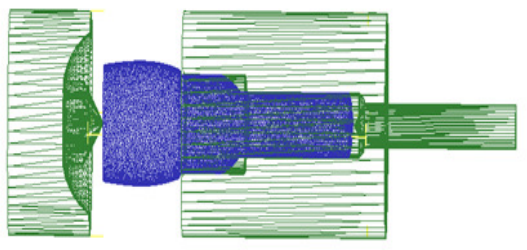

(a) Before formation

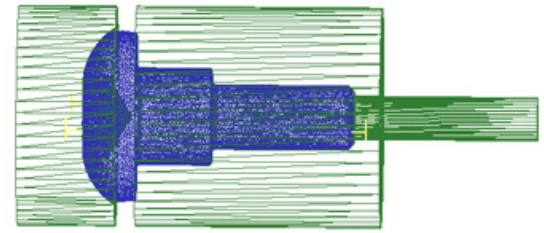

(b) After formation

Figure 11. Die assembly diagram at the $3^{\text {rd }}$ stage before and after forging.

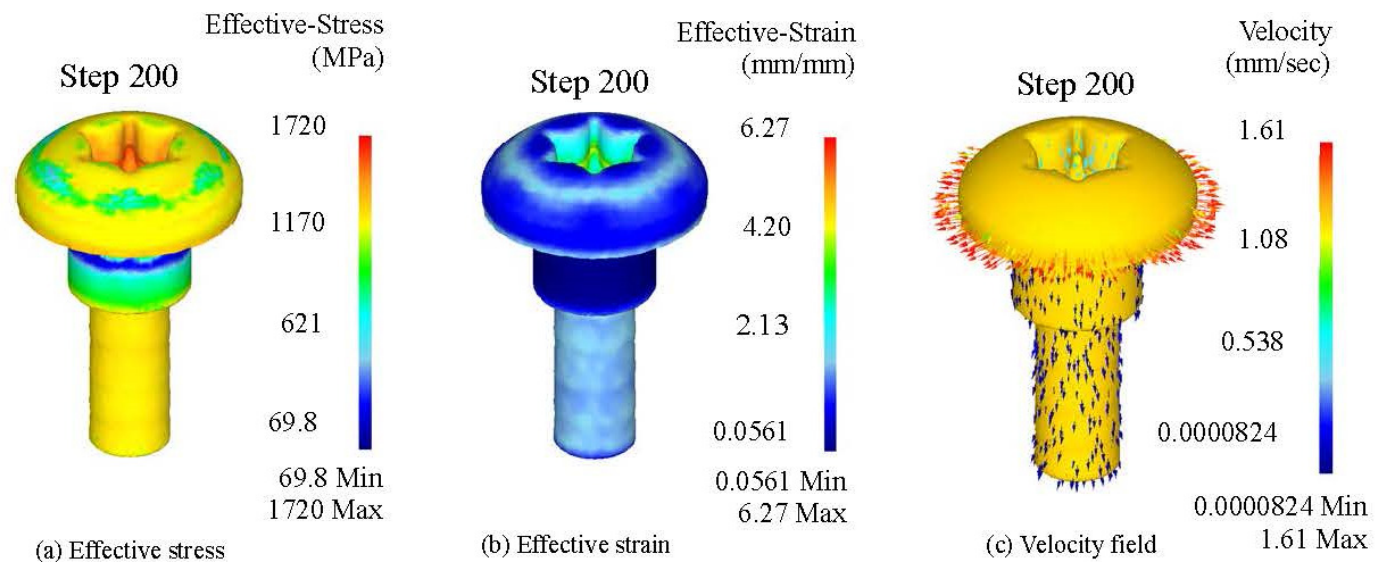

Figure 12. Effective stress, effective strain, and velocity field at the $3^{\text {rd }}$ stage.

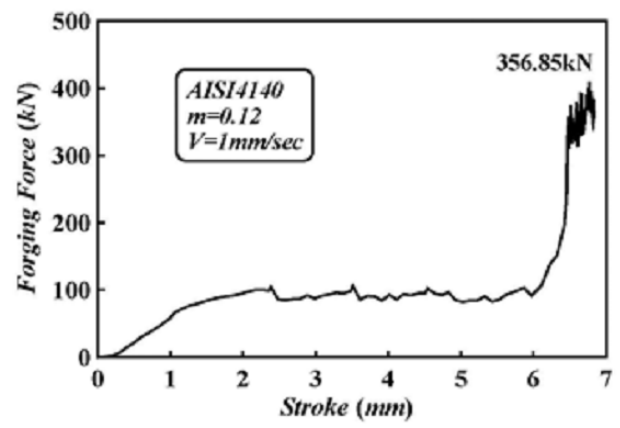

Figure 13. Forging force at the 3rd stage. 
After completing the $3^{\text {rd }}$ stage finite element simulation, it can be known about the effective stress, effective strain, velocity field, and forging force, as shown in Fig. 12(a), its effective stress is higher than the previous 2 stages, where the stress is significantly centralized on the torx-pin head, which the maximum effective stress could be reached to $172 \mathrm{MPa}$. Fig. 12(b) is the effective strain diagram, the maximum effective strain is $6.27 \mathrm{~mm} / \mathrm{mm}$, and centralized on the torx-pin head bottom. Fig. 12(c) is the velocity field distribution diagram, the highest flow velocity is on the round head, and the highest flow velocity is $1.61 \mathrm{~mm} / \mathrm{sec}$. The maximum forging force could be reached to $100 \mathrm{kN}$, as shown in Fig. 13 , and the force is suddenly raised in the process of torx-pin head forming, the maximum value has reached to $356.85 \mathrm{kN}$.

\subsection{Forging force for each stage}

The forging force for each stage can be summarized in Fig. 14 and Table 3, the forging force is very even at first in these 3 stages; however it needs to form the torx-pin head and presses the round head to the required dimension, thus the force is suddenly raised at the 3rd stage. From Table 3, the total forging force is $537.83 \mathrm{kN}$ which does not exceed the rate forging force of machinery, $600 \mathrm{kN}$.

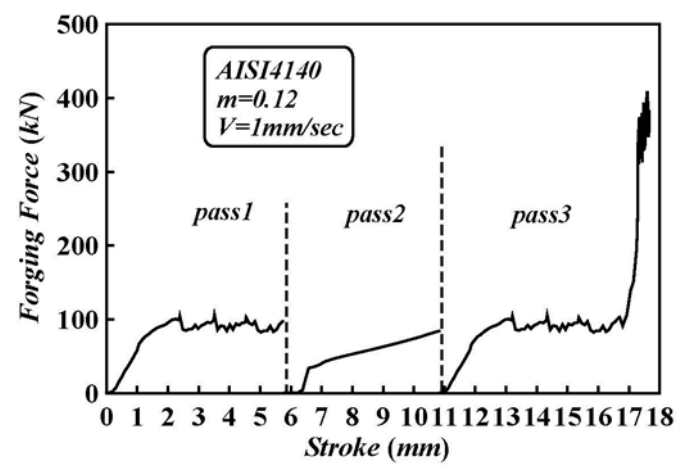

Table 3. Summary of forging force for each stage.

\begin{tabular}{|l|l|}
\hline $\begin{array}{l}\text { Stage } \\
\text { Number }\end{array}$ & Forging Force $(\mathrm{kN})$ \\
\hline Pass 1 & 97.03 \\
\hline Pass 2 & 83.99 \\
\hline Pass 3 forging & 356.85 \\
\hline $\begin{array}{l}\text { Total forging } \\
\text { force }\end{array}$ & 537.83 \\
\hline
\end{tabular}

Figure 14. Forging force for each stage.

\subsection{Experimental verification}
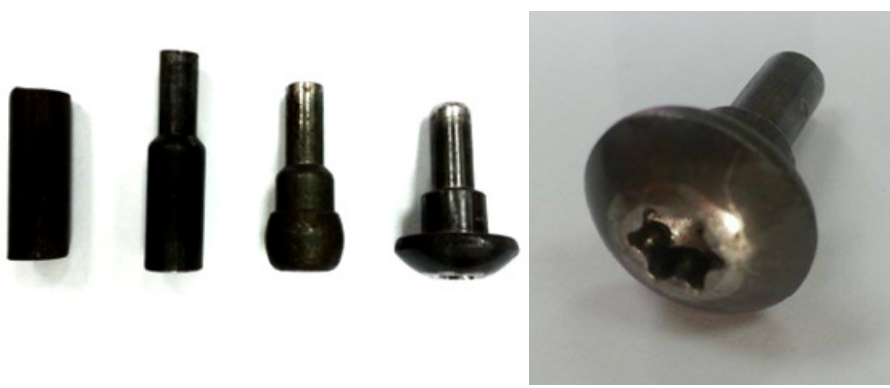

Figure 15. Forging parts for each stage

According to the FEM simulation to check the feasibility of dies, the dies for each stage can be made to perform the realistic experiments to get the forging parts for each stage, as shown in Fig. 15. 
Table 4. Comparisons of FEM result and experiment.

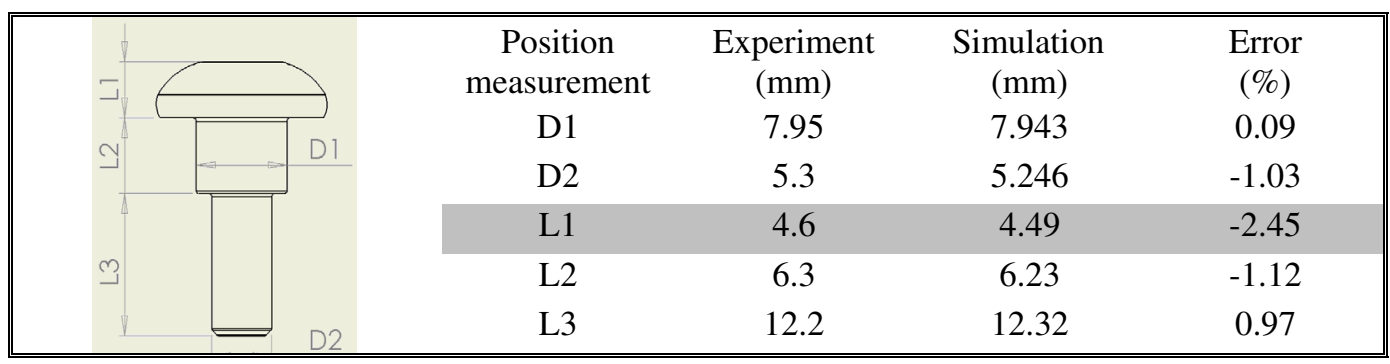

The dimensions of product between FEM result and experiment can be compared in Table 4. The maximum error on L1 position is $2.45 \%$, the FEM simulation is in agreement with the experiment. Therefore, the FEM simulation model proposed can be acceptable for the trox-pin screw manufacture.

\section{Conclusions}

In this study, SolidWorks and DEFORM-3D have been to implement the finite element simulation analysis, it shows that DEFORM-3D can improve the die design to reduce the die cost and design time. It also can obtain the effective stress, effective strain, velocity field, and forging force under various forming conditions for each stage. Lead time and technology development time of product design would be greatly reduced, as well as lowers the expensive on-site testing costs so as to increase the benefit of die design, reduce material cost, and increase company's economic benefit. Therefore FEM simulation can actually apply to the multi-stage forging. Moreover, it uses the dimension simulated by DEFORM-3D to compare the dimension of actual product, and the biggest error for L1 is $2.45 \%$ which is very close to the actual dimension of product. The applicability of this simulation can be proved, thus this study can be a reference for the die design of the fastener industry.

\section{References}

1. G. Li, J.T. Jinn, W.T. Wu, and S.I. Oh, Recent development and applications of three-dimensional finite element modelling in bulk forming process, Journal of Materials Processing Technology, 113, 40-45 (2001)

2. S.I. Oh, W.T. Wu, and K. Arimoto, Recent development in process simulation for forming process, Journal of Materials Processing Technology, 111, 2-9 (2001)

3. C.W. Shih, G.Y. Tzou, and K.H. Chang, Multi-stage forming analysis and experiment of flange sleeve, Journal of Chinese Society of Mechanical Engineers, 35 (3), 243-250 (2014)

4. S.Y. Hsia, Optimization of microextrusion preforming using taguchi method, Mathematical Problem in Engineering, Article ID 305797 (2013)

5. K. Lange, A. Hettig, and M. Knoerr, Increasing tool life in cold forging through advanced design and tool manufacturing technique, Journal of Materials Processing Technology, 35, 495-512 (1992)

6. Y. Nagao, M. Knoerr, and T. Altan, Improvement of tool life in cold forging of complex automotive parts, Journal of Materials Processing Technology, 46, 73-85 (1994)

7. M. Knoerr, K. Lange, and T. Altan, Fatigue failure of cold forging tooling: causes and possible solutions through fatigue analysis, Journal of Materials Processing Technology, 45, 57-71 (1994)

8. J.L. Wang, M.W. Fu, and J.Q. Ran, Analysis and avoidance of flow-induced defects in mesoforming process: simulation and experiment, International Journal of Advanced Manufacturing Technology, 68, 1551-1564 (2013)

9. C.W. Shih, G.Y. Tzou, and K.H. Chang, Effects of forging stream line on tensile strength using FEM simulation, Advances in Mechanical Engineering, Article ID 216246 (2014) 
10. M.C. Sun, G.Y. Tzou, and L.A. Zheng, Processing animation simulation and FEM analysis of multi-stage cold forging of stainless automotive battery fastener, Indian Journal of Engineering \& Materials Science, 20, 219-224 (2013)

11. K.H. Chang, C.W. Shih, and G.Y. Tzou, Defect improvement of extrusion dies using combination of FEM stress analysis with Taguchi method, Transactions of the Canadian Society Mechanical Engineering, 39 (3), 729-738 (2015) 